\title{
WILLIAM THAYER ARTEAGA: "LA GENTE, HASTA AQUELLAS PERSONAS MÁS CULTAS, NO SABE CUÁL ES EL DERECHO VIGENTE EN CHILE PORQUE LO ESTÁN MODIFICANDO A CADA RATO Y UNO NO ALCANZA A APRENDERSE UNA LEY CUANDO YA ESTÁ REEMPLAZADA POR OTRA”.
}

- A sus 93 años de edad, este destacado abogado laboralista, ex ministro de Estado y ex senador institucional, todavía se mantiene vigente, ocupado de los asuntos del mundo del trabajo. Y sigue muy de cerca el curso de los acontecimientos laborales.

- “Fui -señala en su libro 'Memorias Ajenas'- hombre público de segunda fila, en cuanto actor, pero de primera, como testigo privilegiado".

- Está convencido que la especialización y la alta calificación hace más independiente al trabajador: "Al calificado no lo echan, él se va porque lo llaman de otras partes".

\section{Por ARTuro CASTillo Vicencio}

William Thayer, nacido el 12 de octubre de 1918, perteneciente a la segunda generación de los Thayer nacidos en Chile, entró de lleno al mundo laboral cuando en los años cuarenta, recién egresado de la Escuela de Derecho de la UC, puso en jaque a las autoridades del Banco del Estado, logrando, en unas pocas horas, el embargo del edificio de la entidad, el mismo que hoy existe en la Alameda, entre las calles Bandera y Morandé, y de todas sus instalaciones para llamar la atención pública de un conflicto que se había suscitado entre los ejecutivos y sus trabajadores. Esa misma mañana, mientras desayunaba en el café Astorias, Carlos Vergara, asesor legal del Sindicado de Empleados del Banco del Estado, le había pedido ayuda para resolver el asunto que podía desembocar en una huelga de insospechadas consecuencias.

El caso fue ampliamente divulgado en la prensa de aquella época y Thayer entró, gracias a esa gestión, por la puerta ancha al mundo del derecho laboral.

Esa acción llamó la atención del padre Alberto Hurtado Cruchaga quien lo llamó para que trabajara junto a él en la defensa de los derechos de los obreros, en el fortalecimiento de los sindicatos y en la labor social que desplegaba por esos años. Además, gracias a esa intervención en el Banco, se convirtió en uno de los abogados favoritos de las nacientes organizaciones de los trabajadores cupríferos del país.

Paralelamente al ejercicio de la profesión, Thayer Arteaga estaba inmerso en el mundo académico (hizo clases en las universidades Católica y de Chile) y en el ámbito social y político. Por esos años era presidente nacional de la Juventud Católica y estaba incorporado al grupo de jóvenes políticos que fundaron la denominada Falange Nacional, hoy Partido Demócrata Cristiano, en el cual militó por largos años hasta su expulsión en septiembre de 
1973 tras manifestar su inmediata simpatía por el movimiento militar que derrocó al Presidente Salvador Allende. "Pinochet -señala- se adelantó a las intenciones que tenía Allende de transformar a Chile en un satélite de la Unión Soviética. Y ahora que no existe la URSS, ¿qué nos habría pasado a nosotros?, ¿estaríamos como Cuba?”.

\section{SU VISIÓN DEL MUNDO LABORAL}

\section{¿Cómo vislumbra usted el futuro del derecho del trabajo y de la seguridad social?}

-Yo creo que va a pasar a ser derecho del trabajo dependiente. El Código del Trabajo en Chile es un Código del trabajo dependiente. O sea, solo atiende al trabajador que está prestando servicios en calidad de empleado de una empresa. Y el trabajador independiente no entra en el Código del Trabajo. Esa dependencia, a mi juicio, tiende a debilitarse, porque la dependencia, inicialmente en el concepto del Código del Trabajo, era jurídica y económica. El empleador sabía mucho más y el trabajador era muy pobre y la inmensa mayoría eran obreros y, culturalmente, analfabetos. Ese proceso creó un derecho del trabajo que fue fundamentalmente para obreros, para trabajadores manuales, para la inmensa masa del proletariado, que se les denominaba así porque no tenían más bienes que su propia prole. Este grupo era inculto, vivía en malas condiciones, eran patipelados. Pero con el tiempo el trabajador tendió a ser menos inculto, a prepararse más y a ser, por lo tanto, menos dependiente. Y ese proceso está en marcha.

\section{Los niveles de especialización le han dado menos dependencia.}

-Exactamente. La definición que separaba al obrero del empleado era en que en el primero predominaba el esfuerzo físico en lugar del intelectual. Y al comienzo había un empleado por cada 15 obreros. Por eso el eje del movimiento obrero era la lucha de la inmensa masa inculta contra una empresa que era dueña de los medios productivos y que mantenía al trabajador ajeno a la empresa pagándole una plata solo para que trabajara. Todo ese mundo está cambiando y el trabajo está siendo cada vez más parte de la empresa. Hoy la empresa es una asociación de capitalistas y trabajadores para producir. Y cada vez más, de representantes de los capitalistas, que también son trabajadores, y ellos tienen más capacidad de ahorro y capitalizan. Este mundo, en que estaba separado el capital del trabajo, se ha ido modificando. Hoy los capitalistas delegan la gestión de sus empresas a sus trabajadores a técnicos que administran los capitales. Los ejecutivos de las empresas de hoy no son los dueños ni es la gente más rica, sino que es la gente más capaz. Entonces, a mi entender, el futuro del derecho del trabajo es el que rige la presencia humana versus la presencia de la máquina.

\section{Por lo mismo que usted dice, en el mundo de hoy el trabajo tiene un valor indiscuti- ble. ¿A su juicio, ese es el único sentido?}

-No, porque históricamente el mundo laboral está todavía en transición. Usted todavía encuentra actividades que son propias del siglo XIX, van quedando menos, pero todavía subsisten. Entonces, el grueso del problema laboral es el proceso de transformación del trabajador de dependiente económico y jurídico a un trabajador independiente económicamente y jurídicamente asociado. Ese es el punto. En la empresa, desde que se produjo el 
mundo asociativo, lo voy a decir así, el trabajador independiente era dependiente. En cambio, el trabajador sindicalmente asociado es socio e imprescindible. La empresa puede prescindir de un trabajador aislado, pero no puede cambiar a todos los asociados sindicalmente.

\section{¿Y los sindicatos han estado a la altura de estas transformaciones?}

-Mire, ¿qué error cometieron los sindicatos? Pues que optaron, explicablemente, pero equivocadamente, por la forma del sindicato de empresas y no por la forma de sindicatos supraempresa que pueden ser asociaciones de trabajadores por áreas productivas, por profesiones o por lo que se quiera. Fíjese que al trabajador altamente especializado y calificado no le conviene la negociación colectiva por grandes áreas, porque ese proceso tiene de subir al menos calificado y a bajar al que sí tiene suficiente entrenamiento en su especialidad. La negociación colectiva busca un promedio que favorece al que gana menos y perjudica al que gana más.

\section{Y en este sentido, ¿qué rol juegan las llamadas empresas multi -RUT?}

-Aquí hay una tremenda ignorancia de la ley que nos rige y de la creencia de que las costumbres son las leyes. Y eso no es así. Es muy distinto. El RUT es una agrupación de nombres para fines fiscales. Yo tengo un RUT para pagar mis impuestos, las empresas tienen un RUT para fines tributarios. Pero para fines laborales, eso no tiene nada que ver. La empresa es una institución para producir, no para pagar impuestos. Ninguna disposición del Código del Trabajo establece que se negocia por RUT. Y el RUT de una empresa implica un ordenamiento fiscal para ver qué actividades son las que considera el fisco para fines tributarios. Ahora, esto puede tener implicancias en la determinación o en la calificación de las utilidades de las empresas.

\section{¿Y qué tiene que ver con el mundo laboral? \\ -Nada.}

\section{¿Entonces?}

-Es que todo esto parte por una cosa equivocada, perdóneme, pero voy a decir un disparate, de creer de lo conveniente que es en Chile la negociación por empresas y la sindicalización por empresas. Es conveniente negociar por grupos de empresas, pero no es conveniente la asociación sindical por empresas porque eso, en el caso de Chile, nos deja al margen del derecho a sindicalización del 80\% de los trabajadores. Tan simple como eso.

\section{No todos lo ven así...}

-Es que hay una tremenda confusión producto de la ignorancia de la gente. La gente, hasta aquellas personas cultas, no sabe cuál es el derecho vigente en Chile. Y no lo sabe porque lo están modificando a cada rato y la gente no alcanza a aprenderse una ley cuando ya está reemplazada por otra. Yo que soy bastante experto en el derecho laboral tengo que estar constantemente consultando el texto actualizado del libro del trabajo para saber cuál es la última norma vigente. Y yo creo que nos gusta tomar las grandes líneas. El problema que existe es el hábito de asociarse por empresas en un país en que el objetivo es una fuerza 
suficiente al trabajador con un sindicato grande. Un sindicato chico es muy débil. Pero que sea fuerte no es sinónimo hoy de que se logre una buena negociación. La negociación hoy debiera ser por grupos homólogos y no por grupos fuertes.

\section{¿Qué le dicen los términos Reforma Previsional y Pilar Solidario?}

-Yo creo que la última reforma previsional fue buena y que la previsión tiende a ser solidaria y a organizar a los beneficiarios dentro de un rango en que nadie puede ser imponente previsional a un nivel inferior al ingreso mínimo y nadie es imponente a un nivel superior al tope. O sea, la previsión es siempre de base solidaria e implica que un trabajador en que durante el tiempo en que menos enfermedades y menos responsabilidades tiene puede financiar su salud casi sin costo. Pero, en la medida en que pasa el tiempo, el trabajador tiende a producir menos y a gastar más en salud. Entonces, sustancialmente el sistema de la previsión es que todo trabajador en el sistema de las Isapres se corta este esquema y hace que todo trabajador es ambicionado por el sistema cuando es sano y es repelido por el sistema cuando se enferma porque es caro. O sea, hace del viejo un ser detestable en el momento en que más necesita de la previsión. Estos pilares solidarios implican una reforma en la buena línea. Ahora, esto está partiendo y yo le puedo decir que la última fue una buena reforma previsional. Y lo que hizo una mala reforma fue el sistema de Isapres en cuanto estableció que cada institución de salud era libre para recibir o no recibir según que les dé o no muchos problemas. Eso fue muy absurdo, pero se ha ido modificando.

\section{¿Flexiseguridad o trabajo flexible?}

-Esto responde, fundamentalmente, al proceso educacional y de capacitación. Hoy día el trabajador ve en su principal factor de estabilidad su calificación profesional. El trabajador altamente calificado es buscado. Al calificado no lo echan a cada rato, sino que él se va. ¿Qué pasaba cuando la calificación profesional era la excepción? Allí no había más defensa que la inamovilidad funcionaria. O sea, antes eran la improductividad y la inamovilidad, y hoy día son movilidad y productividad. Al que tiene alta calificación no le conviene estar amarrado. La flexibilidad son variaciones sobre el tema de que a través del tiempo el respaldo de permanencia activa en el mundo laboral del trabajador pasó de la fuerza del número a la alta calificación.

\section{CALAMA, LA CIUDAD DEL PECADO}

Actualmente, su empeño y sus esfuerzos están dedicados a sacar adelante el Plan Calama, Ciudad Universitaria (PCCU), destinado a recuperar la ciudad en aspectos morales, familiares y culturales, en los cuales, según él, muestra un enorme déficit respecto del resto de las ciudades del país.

Calama, según explica, era visitada como lugar de entretención para los mineros del cobre, los que bajaban a la ciudad sin sus familias y con el mero propósito de buscar diversión, "por eso en Calama hay tanto alcoholismo y prostitución", advierte.

"No sé si lo vamos a lograr", señala. Eso va a depender del interés que muestre Codelco y del financiamiento colateral que llegue para esta iniciativa.

El PCCU ha sido diseñado básicamente por William Thayer, pero en su confección 
han participado junto a él destacadas personalidades del mundo académico, público y social, tales como el director de la Escuela de Historia de la Universidad Finis Terrae, Álvaro Góngora; Ximena Cruzat, y el decano de la Facultad de Ciencias Sociales de la Universidad Católica, Pedro Morandé, entre otros.

\section{¿En qué consiste ese plan?}

-Corresponde a la inmensa y hermosa tarea de asegurar el destino social digno y constructivo de la población que Codelco tenía viviendo en Chuquicamata y que trasladó íntegramente el 2008 a asentarse en Calama. Esto significó llevar 25.000 personas a una ciudad de poco más de 100.000 habitantes. No se olvide usted que por esta ciudad, capital de la provincia de El Loa, pasa la mayor riqueza que Chile produce y de la cual depende. No hay otra comuna que reciba esa riqueza que solo pasa por Calama, pero no queda aquí.

\section{¿No hay universidades allá?}

-No, pero estamos buscando tentáculos para preparar a Calama para que sea capaz de darle cabida a una universidad con el apoyo de la Universidad Católica del Norte.

Pero, entonces, no se trata solamente de una universidad, sino que de un centro de formación técnica porque la minería requiere de especialistas y mandos medios.

-Por eso es que la tarea no es crear solamente una universidad, sino que hacer de Calama una ciudad que sea apta para recibir a una universidad.

\section{¿Acaso no está apta hoy?}

-Cuando se puso término al sistema de campamentos de Chuquicamata y se trasladó a toda esa población a residir en casas propias en Calama, la preocupación de Codelco era qué hacer para que esa población se quede en Calama. Yo les dije que si les ofrecen a los hijos de los mineros buena educación y les aseguran posteriormente un trabajo, esa gente se quedará allí. Al menos los 100 años de explotación minera en la zona le han dado a Calama la infraestructura suficiente para ser un gran centro de actividades de importancia en el mundo.

\section{¿Y, entonces?}

-Lo que pasa es que Calama es deficitaria en tres áreas.

\section{¿Cuáles?}

-En familia, en cultura y en los aspectos morales de la sociedad. No es una población que haya fortalecido la institución familiar como base de vida para el trabajador. Por el contrario, desde el desierto los trabajadores iban solos a la ciudad, dejaban la familia lejos.

\section{¿Hay mucha prostitución en Calama?}

-Claro y eso enreda todo el problema moral y familiar que le estoy explicando. 


\section{¿Se han interesado en este proyecto los parlamentarios de la zona?}

-No, ninguno. Ni siquiera he tomado contacto con ellos.

\section{¿Y las autoridades provinciales y comunales? \\ -Tampoco.}

\section{LA RELACIÓN DE THAYER CON PINOCHET}

William Thayer sintió simpatía inmediata por el gobierno militar. Augusto Pinochet, cuando era teniente recién egresado de la Escuela Militar, había sido su oficial instructor cuando el jurista hizo su servicio militar en el regimiento de Infantería No 2, Maipo, de Playa Ancha, Valparaíso, en el año 1939.

Desde entonces mantuvieron una permanente amistad. Igual que lo hizo, al año siguiente, con los fundadores de la Falange Nacional, movimiento del que también participó activamente. Su cercanía con el grupo precursor de la democracia cristiana se debieron por una parte a sus permanentes contactos con la Iglesia, especialmente con el padre Alberto Hurtado, y a que en la Universidad Católica de Chile, donde estudiaba derecho, fue alumno, en 1942, de la cátedra de derecho del trabajo que dictaba Eduardo Frei Montalva, quien, a su vez, cuando era ministro de Obras Públicas le encargó su primer trabajo profesional como abogado.

Más tarde, durante el gobierno de Frei (1964-1970) ocupó la titularidad de los Ministerios de Justicia y del Trabajo y fue suplente por unos meses en el Ministerio de Educación.

Pero aparte de la atracción que sintió por el gobierno militar, la democracia cristiana decidió expulsarlo de sus filas cuando se formó una confusión porque William Thayer fue nombrado como uno de los representantes de la Unesco para América Latina en reemplazo del poeta y Premio Nobel de Literatura, Pablo Neruda, quien había fallecido de cáncer a los pocos días del golpe de estado que instaló a la Junta Militar al frente del gobierno de Chile.

Thayer cuenta que la confusión se produjo porque "ellos creyeron que yo había sido nombrado embajador ante la Unesco, con sede en París, por los militares. Sin embargo, no fue así. Fue la propia Unesco la que me propuso el cargo. Eso se lo expliqué una vez a mi amigo Patricio Aylwin, quien había escrito artículos en tal sentido.

\section{¿Y qué le dijo Aylwin?}

-Nada. Solo exclamó ¡Ah! pero igual me expulsaron. Además, no se olvide usted que al momento del golpe yo era rector de la Universidad Austral de Valdivia, cargo que ocupaba por elección de la comunidad universitaria desde 1968, del que fui destituido por las autoridades un mes después del golpe.

\section{¿Y no le valió de nada su amistad con Pinochet?}

-Nunca le dije nada al respecto. 


\section{Pero después sí tuvo mayor cercanía con él...}

-Claro una vez me llamó y me dijo que necesitaba con urgencia gente de confianza en Estados Unidos. "Elige el cargo que quieras", me dijo. Pero no acepté.

\section{¿Y su cercanía con él era política o de amistad?}

-Es que le explico, mis cercanías con los gobernantes radican en lo que hace un gobierno o lo que evita un gobierno. Y Pinochet encabezó un gobierno eficaz que nació de un esquema por evitar el intento de que Chile se transformara en un satélite soviético.

No obstante, más adelante ocupó diversos cargos asesores del gobierno: Entre ellos, integró la Comisión legislativa, fue miembro del Consejo de Estado, asesor del Ministerio de Relaciones Exteriores y, finalmente, Pinochet lo nombró senador designado, precisamente, por su condición de ex rector de una universidad reconocida por el Estado, cargo del que lo había destituido en 1973.

Y en 1987, junto al actual ministro de Defensa Nacional, Andrés Allamand, y Sergio Onofre Jarpa fue uno de los fundadores del partido Renovación Nacional.

Hoy, William Thayer Arteaga, padre de siete hijos que le dio su esposa, la escritora Alicia Morel Chaigneaux, hermana del padre de la actual primera dama de la nación, vive tranquilamente en su discreta residencia del barrio Amapolas de Providencia, a escasos metros y en la misma calle en que tiene su casa el ex presidente Patricio Aylwin. Pero ya no se visitan. 